\title{
Research into Surface Soil Resource Utilization Effect in the Expressway
}

\section{Construction}

\author{
Zi-Long CAO ${ }^{1, a}$ and Shu-Xue CHEN ${ }^{1, b, *}$ \\ ${ }^{1}$ Academy of Science under the Ministry of Transport, Beijing City 100029 \\ acaozilong@126.com, bchenshuxue@moccats.com.cn \\ ${ }^{*}$ Corresponding author
}

Keywords: Expressway, Surface soil resource, External-soil base material, Greening effect.

\begin{abstract}
In order to test the effect of surface soil resources in highway construction, surface soil resource is used as the external-earth base material to conduct the external-soil spray-seeding greening test on the expressway slope. Research results show that using surface soil as main external-soil base material to conduct slope external-soil spray-seeding greening can effectively increase the average coverage of slope vegetation, remarkably promote slope vegetation to naturalized plant community succession and make slope vegetation to gradually converge with the neighboring natural slope plant community.

Surface soil arising from the clearing construction of expressway is abundant in large quantities of such nutrients as humus, organic matter, nitrogen, phosphorus and potassium, and too often contains rich indigenous plant seed and soil microorganism resource. Hence, it is a precious recycling resource. The soil seed bank consisting of living seeds in surface soil resource is the potential plant population or community as well as the material basis of natural regeneration of vegetation [1]. Some developed countries including the US and Japan attach great importance to topsoil stripping and utilization, has possessed the relatively mature management system and technical means and conducted related researches [2-4]into the vegetation recovery effect through surface soil utilization. Study shows that refilling utilization of natural surface soil after stripping can increase biodiversity [5-6] of new surface soil, and accelerate the vegetation succession [7] beneficial to the early-stage development of indigenous shrub wood. Surface soil resource utilization is increasingly being stressed in the vegetation recovery in the expressway construction and has been simply utilized in part of expressway construction. For example, the stripped surface soil is utilized to cover the expressway disturbance region or refill for reclamation [8-10]. Relying on Guangzhou-Lechang expressway project in progress, the research takes surface soil as main external-earth base material and combines external-soil spray-seeding technology to conduct the beneficial trial for further probe into the utilization effect and value of surface soil resource in the expressway construction by conducting the test research into slope greening effect comparison.
\end{abstract}

\section{General Situation of Research Area}

The research relies on the construction project of Guangzhou-Lechang expressway. The trial section lies in Lixi town, Yingde city, Guangdong province, the study area is in the mid-subtropical zone and wet monsoon climate area, affected by monsoon all the year around, northeast monsoon prevailing in winter, southwest and southeast monsoon prevailing in summer. In the area, the average precipitation is $2400 \mathrm{~mm}$, the evaporation capacity $1718 \mathrm{~mm}$, the annual average sunshine 
duration 1631.7 hours and the annual average temperature $21.1^{\circ} \mathrm{C}$; the soil type is mainly latosolic red soil.

\section{Research Method}

\section{Test Slope Setting}

The research takes the slope on the right of Guangzhou-Lechang expressway in progress with the stake number: K206+143 K206+250 as experimental slope and the corresponding left slope of the section as comparison slope. The height of the experimental slope is $7 \mathrm{~m}$, with the slope ratio of $1: 1$, being soil slope; the height of comparison slope is $11 \mathrm{~m}$, with the slope ratio of 1:1, being soil slope. The vegetation in the section near the experimental slope is mainly pteridophyta, growing vigorously.

\section{Test Material}

In the research, the soil material for external-soil base material of test slope is surface soil collected in the clearing construction of nearby roadbed while the soil material for external-soil base material of comparison slope is non-surface soil.

\section{Test Program}

\section{Construction Technology}

The test slope and comparison slope selected in the test are both constructed with the external-soil spray-seeding technology.

\section{Material Ratio Program}

To strengthen the comparability of test slope and comparison slope, the external-soil base material soil for the test slope is completely surface soil while the for the comparison slope non-surface soil, with the ratio program seeing Table 1.

Table 1 Ratio Program of surface soil and non-surface soil in the external-soil spray-seeding base material for test slope for test slope and comparison slope respectively

\begin{tabular}{c|c|c|c}
\hline \multirow{2}{*}{ Item } & \multirow{2}{*}{ Unit } & \multicolumn{2}{|c}{$\begin{array}{c}\text { Ratio of surface soil and non-surface soil } \\
\text { in external-soil base material }\end{array}$} \\
\cline { 3 - 4 } & & Surface soil & Non-surface \\
\hline Test slope & $\%$ & 100 & 0 \\
\hline Comparison slope & $\%$ & 0 & 100 \\
\hline
\end{tabular}

\section{Plant Species Ratio Program}

To strengthen the comparability of test slope and comparison slope, the same ratio program is applied to test slope and comparison slope in spray-seeding plant species selection, with the plant species ratio program seeing Table 2 . 
Table 2 External-soil spray-seeding plant species ratio program for test slope and comparison slope

\begin{tabular}{l|c|c}
\hline \multirow{2}{*}{ Name of plant species } & \multicolumn{2}{c}{ Designed quantity $\left(\mathrm{g} / \mathrm{m}^{2}\right)$} \\
\cline { 2 - 3 } & Test slope & Comparison slope \\
\hline Cynodondactylon & 1 & 1 \\
\hline Indigofera amblyatha & 3 & 3 \\
\hline Rhus chinensis Mill. & 3 & 3 \\
\hline Lespedeza floribunda Bunge & 2 & 2 \\
\hline
\end{tabular}

\section{Construction Time}

There's different completion time of test slope and comparison slope clearing, so the external-soil spray-seeding test construction time differs. The construction time of test slope started on December 22, 2011 and completed on December 23; that of comparison slope started on December 15, 2011 and completed on December 16. The construction time is basically the same and both in the middle and last ten days of December 2011. The same maintenance pattern is adopted after the spray-seeding greening of test slope and comparison slope is conducted.

\section{Slope Plant Observation}

(1) Quadrat setting. The observation method of randomly drawing and fixing quadrat is adopted. For test slope and comparison slope, 3 fixed observation quadrats are set randomly, with each quadrat's size of $1 \mathrm{~m} \times 1 \mathrm{~m}$, fixed with small timber piles at four corners and forming four sides with strings.

(2) Observation content. After external-soil spray-seeding completion, regular observation of fixed observation quadrats set in test slope and natural slope is made, with the observation content including: plant species, coverage, height, growth situation, etc.

(3) Observation time and frequency. Within 60 days after external-soil spray-seeding completion, fixed observation quadrats set in test slope and comparison slope is observed every 10 days, and then every month until October 2013, when the second plant growing season ends.

\section{Results and Analysis}

\section{General Evaluation of Test Slope Greening Effect}

The external-soil spray-seeding construction on the test slope started on December 22, 2011 and completed on December 23. After two plant growing seasons, the surface of test slope was steady without water and soil loss and slope vegetation being mainly dicranopteris dichotoma together with indigenous plant community landscape of local wild weeds and the slope vegetation coverage of $91 \%$, and thus, the plant coverage is high and the whole greening effect of slope is good. See Picture 1 and 2 for the whole comparison results before and after test slope greening.

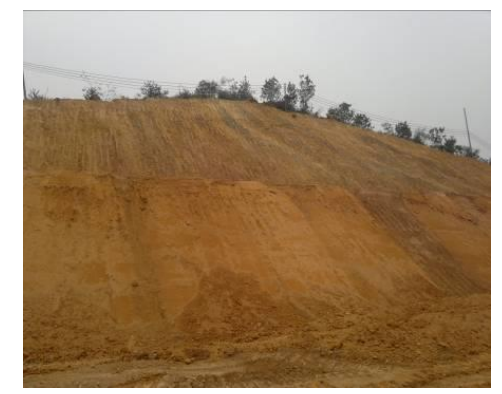

Fig. 1 Situation of test slope before construction 


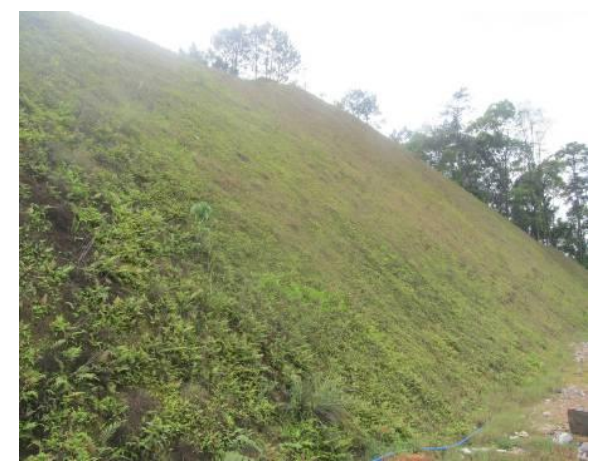

Fig. 2 Whole greening effect of test slope (22 months after construction)

\section{Greening Effect Comparison Evaluation of Test Slope and Comparison Slope}

It can be seen from Picture 3 and 4 that in the initial period of external-soil spray-seeding greening, the average vegetation coverage of test slope is similar to that of comparison slope. 4 months later after construction, the average vegetation coverage of test slope and comparison slope is $72 \%$ and $70 \%$ respectively. After two plant growing seasons, the average vegetation coverage of test slope and comparison slope changes obviously, the average vegetation coverage of test slope and comparison slope is $91 \%$ and $80 \%$ respectively, and the former is obviously higher than the latter.

It can be seen from Figure 5 and 6 that in the initial period of external-soil spray-seeding greening, the vegetation community composition of test slope is similar to that of comparison slope. 4 months later after construction, the vegetation of test slope and comparison slope is mainly cynodon dactylon community, together with artificial herbaceous plant community of such plant species as Indigofera amblyatha, Rhus chinensis Mill and Lespedeza floribunda Bunge after one plant growing season, the vegetation community succession of test slope begins to take place gradually. The plant species with the largest vegetation coverage in the community cynodon dactylon is gradually replaced by indigenous plant species dicranopteris dichotoma. Until the second plant growing season ends, the vegetation community of test slope has evolved into the indigenous plant community with fern dicranopteris dichotoma as main and together with local wild weeds. However, for the comparison slope, after two plant growing seasons, there's no obvious plant community succession, and the vegetation community is still mainly cynodon dactylon community, together with artificial herbaceous plant community of Indigofera amblyatha, Rhus chinensis Mill, Lespedeza floribunda Bunge and little wild weeds. After two plant growing seasons, see Picture 7 and 8 for the comparison of the whole greening effect of test slope and comparison slope.

The test research results show that external-soil spray-seeding greening with surface soil as main external-soil base material can effectively increase the average coverage of slope vegetation and remarkably promote slope vegetation to the succession of indigenous plant community. 


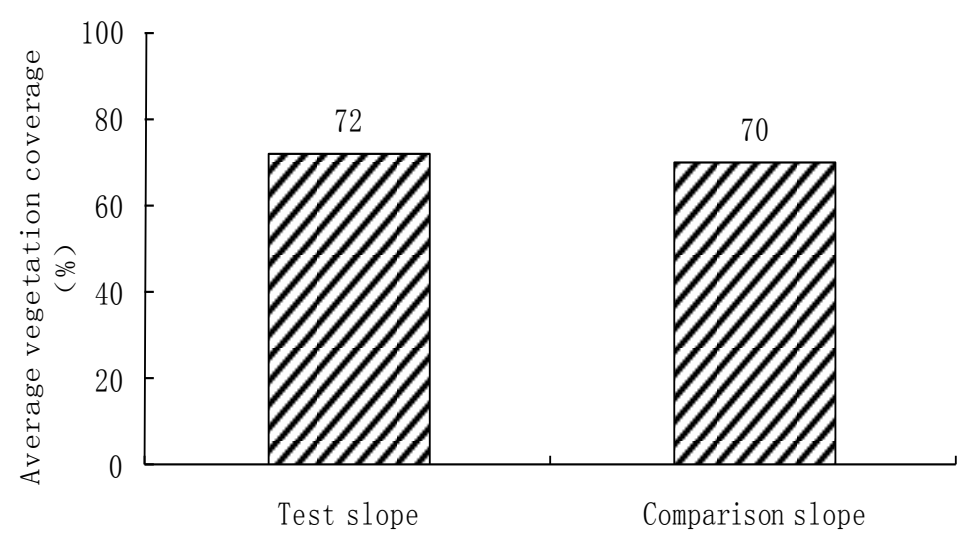

Fig. 3 Average coverage of slope vegetation (4 months later after construction)

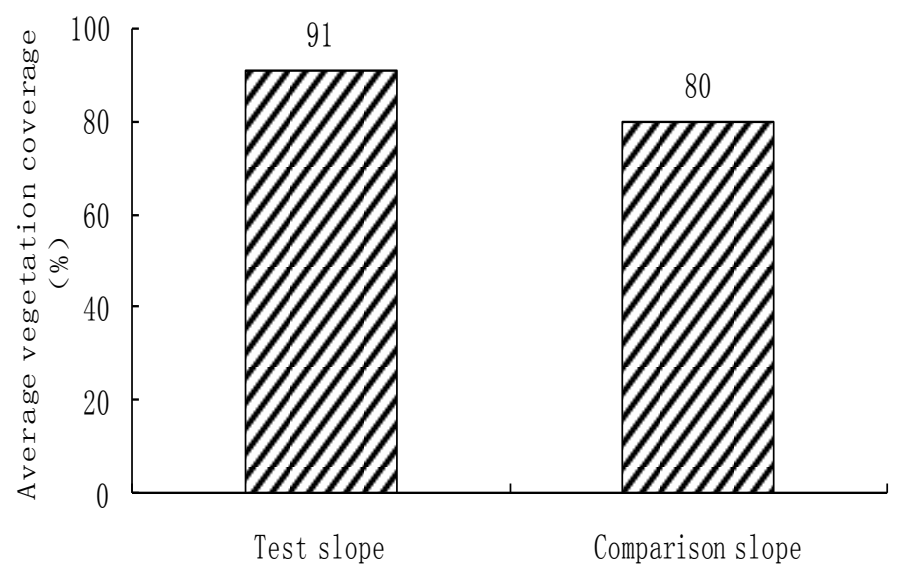

Fig. 4 Average coverage of slope vegetation (22 months later after construction)

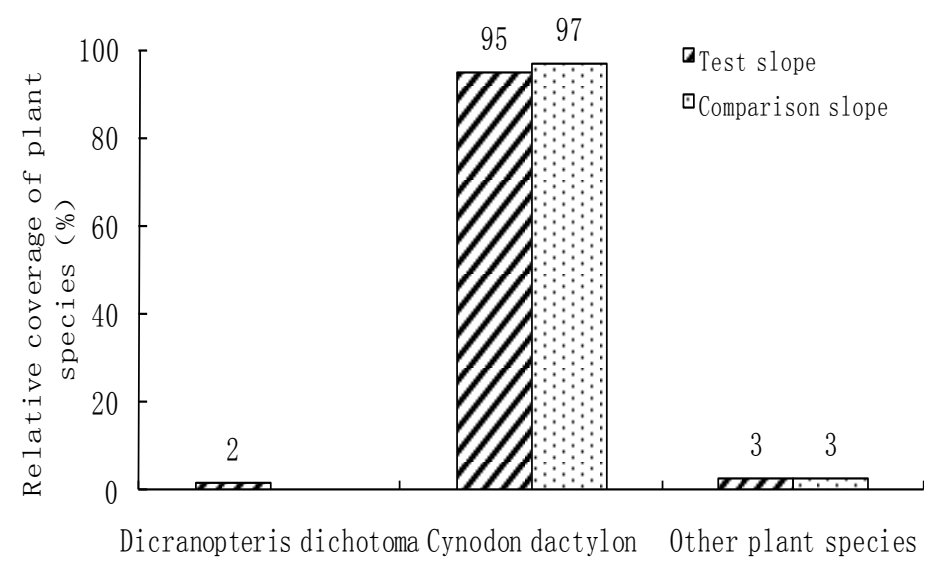

Fig. 5 Relative coverage of slope plant species (4 months later after construction) 


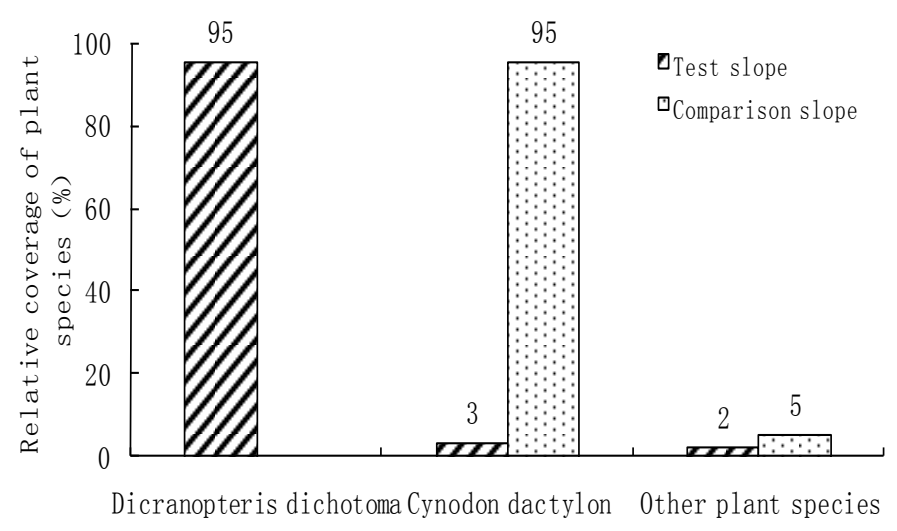

Fig. 6 Relative coverage of slope plant species (22 months later after construction)

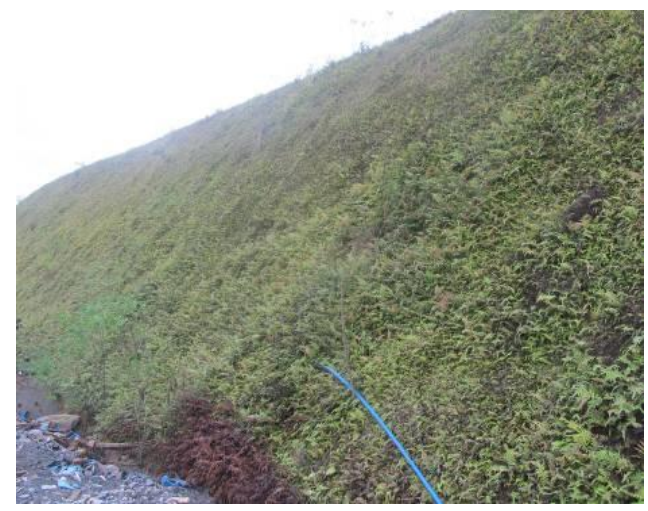

Fig. 7 Whole greening effect of test slope (22 months after construction)

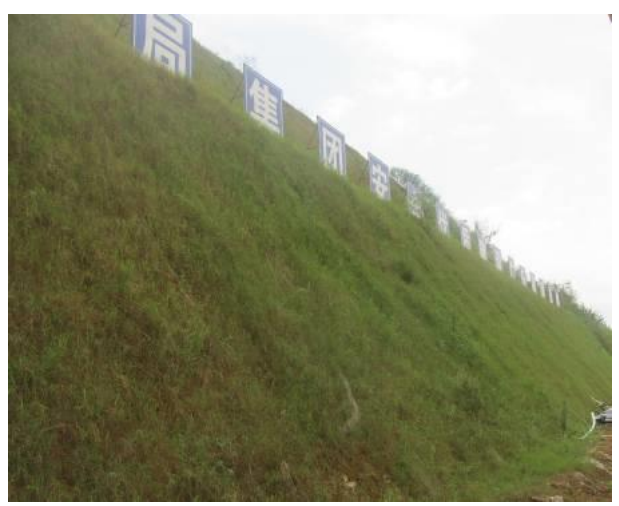

Fig. 8 Whole greening effect of comparison slope (22 months after construction)

\section{Greening Effect of Test Slope and Comparison Evaluation of Natural Slope Vegetation}

After two plant growing seasons, it can be found through the comparison of the test slope greening effect and the natural slope vegetation in the nearby section with the fern as main that after two growing seasons, the features of test slope vegetation community are relatively similar to those of natural slope, and both are indigenous plant community with the fern dicranopteris dichotoma as the overwhelming advantageous plant species. It can be seen from Figure 9 and 10 that the average coverage of vegetation and relative coverage of advantageous plant species of test slope and natural slope are relatively similar, the average vegetation coverage of test slope and natural slope is $90 \%$ and $98 \%$ respectively, and the former is slightly lower than the latter; the relative coverage of 
indigenous plant species dicranopteris dichotoma as the overwhelming advantageous plant species in the community is $91 \%$ and $95 \%$ respectively, and the former is slightly lower than the latter.

Besides, after two plant growing seasons, the average vegetation height of test slope and natural slope is $21 \mathrm{~cm}$ and $44 \mathrm{~cm}$ respectively. The average vegetation height of test slope is obviously lower than that of natural slope. This indicates that after the external-soil spray-seeding greening on the test slope, there's a certain difference in the vegetation growing height between the test slope and natural slope in the relatively short time. After two plant growing seasons, see Picture 11 and 12 for the comparison of test slope greening effect and vegetation of undisturbed natural slope.

The test research results show that the surface soil for expressway slope is used as main external-soil base material for external-soil spray-seeding, which can remarkably promote slope vegetation to succession of indigenous plant community and make slope vegetation gradually converge with the neighboring natural slope plant community.

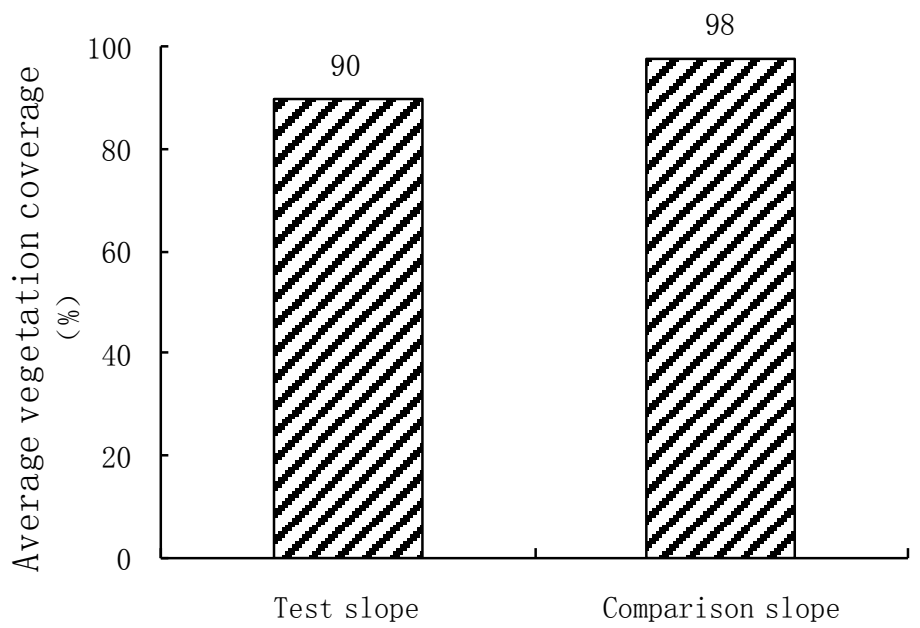

Fig. 9 Average coverage of slope vegetation (22 months later after construction)

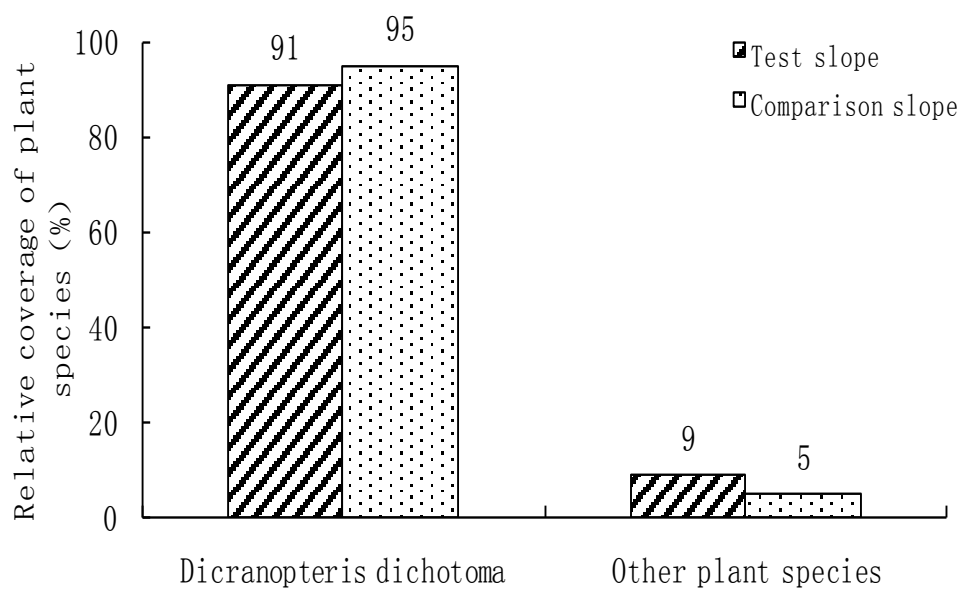

Fig. 10 Relative coverage of slope plant species (22 months after construction) 


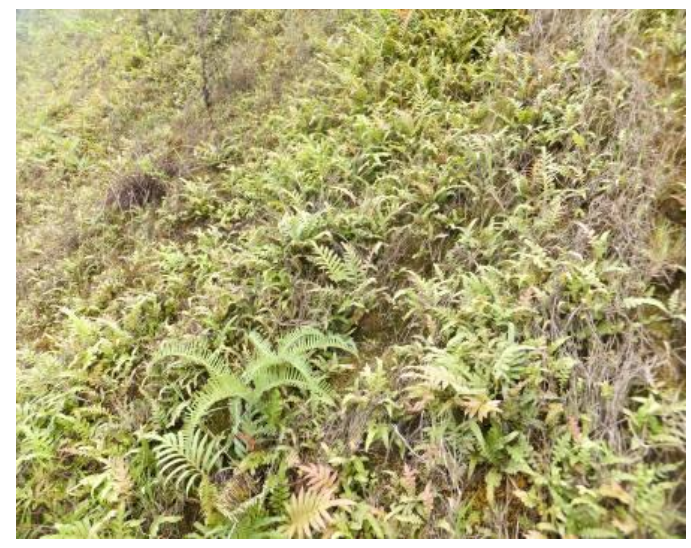

Fig. 11 Vegetation of undisturbed natural slope

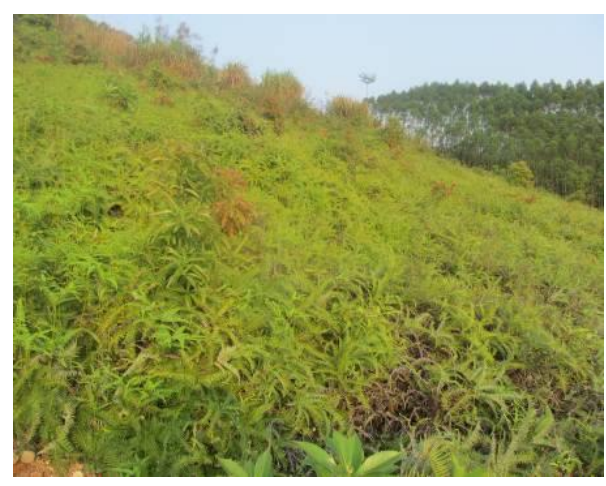

Fig. 12 Test slope greening effect (22 months after construction)

\section{Conclusion}

Through the aforesaid test project and full comparison analysis, the following conclusion is drawn:

(1)With surface soil as main external-soil base material and external-soil spray-seeding technology for slope greening, after two plant growing seasons, slope vegetation gradually grows into the indigenous plant community landscape with fern dicranopteris dichotomy community as main, together with local wild weeds, the average vegetation coverage is about $91 \%$ and the community coverage is good.

(2)The comparison research of the test slope and comparison slope shows that taking surface soil as mainly external-soil base material for external-soil spray-seeding greening can effectively increase the average coverage of slope vegetation and remarkably promote slope vegetation to the succession of indigenous plant community.

(3)After two plant growing seasons, the features of slope vegetation have been relatively similar to the natural slope with fern as main, indicating that taking surface soil as mainly external-soil base material for external-soil spray-seeding can remarkably promote slope vegetation to the succession of indigenous plant community and make slope vegetation gradually converge with the neighboring natural slope plant community.

\section{Acknowledgement}

Fundproiect: science and technology project of the Department of Communications of Guangdong Province "serial technology research in Guangzhou_Lechang expressway construction"(project number: 200901001).

Brief production to the first author: Zi-long CAO (1978-—), male, associate professor, 
graduated from Beijing Forestry University, working in the Science Institute of the Ministry of Transport and mainly engaging in transport environmental protection research.

Brief introduction to correspondence author: Shu-Xue CHEN (1980- -), female, assistant professor, graduated from Nankai University, working in the Science Institute of the Ministry of Transport and mainly engaging in transport environmental protection research.

\section{References}

[1] Moles AT, Drake DR. Potential contribution of the seed rain and seed bank to regeneration of native forest under plantation pine in New Zealand [J]. New Zealand Journal of Botany, 1999, (37):83-93.

[2] Brown G, Al Mazrooei S. Rapid vegetation regeneration in a seriously degraded Rhanterium epapposum community in northern Kuwait after 4 years of protection [J]. Journal of Environmental Management, 2003, (68):387-395.

[3] Zhu Xian Yun. Foreign Surface Soil Stripping Practice and Features [J]. National Resource Economics of China, 2009, (9):24-26.

[4] Liu Xinwei. Japan's Surface Soil Stripping Utilization and Improvement Measures [J]. Land and Resources, 2008, (9):52-55.

[5] Depuit E J. Potential topsoiling strategies for enhancement of vegetation diversity on mined lands [J]. Minerals and the Environment, 1984, 6(3):115-120.

[6] Schladweiler B K, Vance G F, Legg D E, et al. Topsoil depth effects on reclaimed coal mine and native area vegetation in northeastern Wyoming[J]. Rangeland Ecology \& Management, 2005, 58(2):167-176.

[7] Alday J G, Marrs R H. Vegetation succession on reclaimed coal wastes in Spain: the influence of soil and environmental factors [J]. Applied Vegetation Science, 2011, 14(1):84-94.

[8] Wang Weigang, Zhang Qianfeng, Li Neng. Application Practice of Cleared Surface Soil in the Highway Landscape Project. Highway Communication Technology (application technology edition), 2012, (12):358-361.

[9] Wu Feng. Probe into Planning and Utilization of Surface Soil Stripped from Roadbed by Taking Yibao Highway for Example. Communication Science and Technology Heilongjiang, 2009, (8):87-88.

[10] Chen Jican. Brief Discussion on the Practice of Centralized Piling and Utilization of Surface Soil in the Shaogan Expressway Project. Guangdong Science and Technology, 2009, (12):271-272. 